Fanum

Sociológico

\section{Forum Sociológico}

Série II

$21 \mid 2011$

Transformação urbana

\title{
O Fado de Marvila. Notas sobre a origem citadina e o destino metropolitano de uma antiga zona industrial de lisboa
}

João Pedro Silva Nunes e Ágata Dourado Sequeira

\section{(2) OpenEdition \\ Journals}

Edição electrónica

URL: https://journals.openedition.org/sociologico/382

DOI: $10.4000 /$ sociologico.382

ISSN: 2182-7427

Editora

CICS.NOVA - Centro Interdisciplinar de Ciências Sociais da Universidade Nova de Lisboa

Edição impressa

Data de publição: 1 dezembro 2011

Paginação: 33-41

ISSN: 0872-8380

\section{Refêrencia eletrónica}

João Pedro Silva Nunes e Ágata Dourado Sequeira, «O Fado de Marvila. Notas sobre a origem citadina e o destino metropolitano de uma antiga zona industrial de lisboa », Forum Sociológico [Online], 21 I

2011, posto online no dia 05 setembro 2012, consultado o 29 março 2022. URL: http://

journals.openedition.org/sociologico/382 ; DOI: https://doi.org/10.4000/sociologico.382

Este documento foi criado de forma automática no dia 29 março 2022.

(C) CICS.NOVA 


\title{
O Fado de Marvila. Notas sobre a origem citadina e o destino metropolitano de uma antiga zona industrial de lisboa
}

\author{
João Pedro Silva Nunes e Ágata Dourado Sequeira
}

\section{Introdução}

1 Em 1960, um viajante que chegasse a Lisboa de comboio deparava-se à entrada da cidade com uma paisagem facilmente reconhecível: fábricas e armazéns, maquinaria e matérias-primas, pessoas e mercadorias em circulação. Tal viajante com facilidade se aperceberia de uma atmosfera particular, constituída pela laboração industrial e portuária e pela residência operária, envolvendo os lugares que antecediam a sua chegada à gare de Santa Apolónia. Este percurso realizava-se por entre um "mar de chaminés e de gente" que de "Santa Apolónia a Sacavém" pouco deixava entrever que em redor das fábricas e armazéns se encontrava um habitat modesto, pontuado por comércios e alguns equipamentos ${ }^{1}$. Aí, como noutras cidades europeias de então, a proximidade entre a casa e a fábrica exercia os seus efeitos nos lugares, mas também nos ritmos e nas formas como as populações residentes se relacionavam com os bairros onde residiam e com a cidade (Magri e Topalov, 1989).

2 Neste texto esboçamos algumas notas que permitem compreender e interpretar o destino metropolitano de Marvila - freguesia situada na zona oriental da metrópole de Lisboa, marcada durante boa parte do século XX pela laboração industrial e residência operária. Começamos por traçar o seu curso social e urbano, analisando a sua ascensão e queda industrial e explorando o modo como hoje a memória social desses lugares é construída pelos seus residentes numa condição de "relativa invisibilidade social e urbana" (Baptista e Nunes, 2010) e através de uma relação nostálgica com a vida social passada. Em seguida damos conta de como a planificação urbana modelou o espaço, 
povoamento e situação urbana da freguesia, analisando o Plano de Urbanização de Chelas e o programa Viver Marvila. Por fim, apreendemos duas acções que se inscrevem na economia cultural e no meio social urbano de Marvila: Lisboa Capital do Nada e Fábrica Braço de Prata. Interpretamo-las face às propriedades dos circuitos culturais off (Vivant, 2008) e dos creative spaces (Landry e Bianchini, 1998) e discutimos a sua valia na revitalização de uma das mais antigas zonas industriais de Lisboa Oriental.

Daqui resulta uma ilustração multifacetada da não resolvida situação desta zona em relação à metrópole em que se integra. 0 passado industrial e portuário de Marvila surge geralmente afastado dos projectos de reabilitação para a zona. No destino da freguesia é insuficientemente valorizado o papel das populações residentes e dos sectores da economia cultural ali actuantes. O território de Marvila, espaço de vida das populações que ali habitam e trabalham, apresenta um incerto fado urbano.

\section{Origem citadina}

4 Ao longo da segunda metade do século XIX, o crescimento da Lisboa ribeirinha oriental está intimamente relacionado com a indústria, actividades portuárias e uma crescente circulação de pessoas e mercadorias. Na margem do Tejo, vias e pontos de entrada e saída da cidade encontravam-se há muito estabelecidas. Estes nós permitiam a circulação das gentes e mercadorias que tinham a urbe como origem, destino ou ponto de passagem. Na década de 1860 foi decidida a construção da futura Estação de Santa Apolónia. Com a sua edificação, uma série de trabalhos refez a margem do Tejo e reforçou o seu cunho portuário e fabril (Folgado e Custódio, 1999). A disponibilidade de solo favoreceu a conversão das quintas, palácios e conventos da zona em fábricas, armazéns, vilas e pátios.

5 A via-férrea, o porto e a localização de indústrias refizeram o arrabalde oriental da Lisboa do Antigo Regime "que a revolução liberal havia esvaziado de gente e de sentido" (Matos, 1999: 5) e que a expansão do capitalismo industrial oitocentista e novecentista repovoou e re-significou. A escala urbana e industrial de Marvila atingiu então considerável grandeza: fábricas como a dos Sabões, da Borracha, dos Fósforos, da Tabaqueira ou do Material de Guerra, armazéns de companhias como a Abel Pereira da Fonseca ou ainda sedes de empresas como a de José Domingos Barreiros são emblemáticas do curso citadino deste território. À medida que estas e outras actividades se estabeleceram, emergiu um importante centro industrial lisboeta. 0 relevo que Marvila e outros lugares em seu redor evidenciavam enquanto espaço industrial era bem patente aos observadores de final de Oitocentos:

O Inquérito (Industrial de 1890) revela existirem 156 ramos industriais em laboração no I. ${ }^{\circ}$ Bairro da cidade, no qual se integravam as freguesias de Lisboa Oriental. A pequena indústria começava a ser ultrapassada pelas grandes fábricas mecanizadas em vários sectores, albergando centenas de trabalhadores do sexo masculino e feminino. $O$ crescimento pode ser acompanhado através do Boletim do Trabalho Industrial, desde os princípios do século XX até à expansão do porto de Lisboa, para oriente de Xabregas. Todos os autores são unânimes: na Lisboa Oriental encontravam-se os indicadores mais específicos da industrialização da capital. (Folgado e Custódio, 1999: 19)

6 Analisando dados disponíveis no começo da década de 1970, Matias Ferreira (1986: 468) sublinha a persistência da concentração de trabalho industrial na zona e a sua elevada "densidade operária". Da sua pormenorizada análise à frente ribeirinha de Lisboa 
ressalta a especificidade da zona oriental da cidade. Argumenta o autor que a sua constituição como zona industrial é paralela e oposta à formação da centralidade metropolitana no espaço urbano da capital, salientando que:

Em três freguesias (se verifica) um facto relativamente "anormal" em relação às restantes (...): referimo-nos (a) Alcântara, Marvila e Olivais, (onde se) concentra mais de metade (66\%) do emprego industrial de toda a zona ribeirinha enquanto o número de estabelecimentos que ocupa todo esse pessoal não ultrapassa $29 \%$ do conjunto de unidades dessa (mesma) zona. (Ferreira, 1986: 463)

E conclui:

Na zona oriental, o "peso operário" é particularmente significativo em sectores que implicam níveis de tecnologia mais desenvolvida, em especial nos sectores da "química e do vidro" e nos de fabricação de produtos metálicos (ou) equipamento de transporte. (Ferreira, 1986: 471)

8 Nas décadas de 80 e 90, de acordo com Barata Salgueiro (2001: 141), "o declínio industrial de Lisboa acelera-se e a cidade perde peso pelo número de empresas, empregos e Valor Acrescentado Bruto". Revela-se assim o que a autora afirma ser a desindustrialização do centro de Lisboa, o declínio de zonas afectas a sectores produtivos tradicionais e a relocalização na periferia de antigas e novas unidades. Fenómenos que em boa medida contribuíram para que Lisboa entrasse no "período pósindustrial", na expressão de Ferrão e colaboradores (2003: 170).

9 A frente ribeirinha oriental sofreu os efeitos deste processo de desindustrialização. Evidência sistemática das suas origens citadina e industrial, bem como certas marcas do seu curso recente na Lisboa pós-industrial, encontram-se na obra Caminho do Oriente: Guia do Património Industrial (Folgado e Custódio, 1999: 10). É por entre situações de "abandono" e "ruína" (recentes ou mais antigas) que os autores nos guiam à constatação de que aqui faltaram medidas de "conservação e salvaguarda de edifícios e de espólios" e de "recuperação e reconversão". Podia ter sido evitado, argumentam, o "desaparecimento da imagem industrial de Lisboa, tão importante numa concepção cultural da urbe, tal como são os palácios, as igrejas, os conventos ou as quintas e alguns elementos do mobiliário urbano e rural" (Folgado e Custódio, 1999: 10).

\section{"Os resistentes de Marvila"}

10 A história da concentração de actividades industriais, locais de trabalho e famílias operárias nesta zona de Lisboa contribuiu para que se constituíssem formas específicas de relação entre os seus residentes, o meio social local e a cidade. Marvila e o Beato foram durante a primeira metade do século XX espaços de socialização urbana e de integração de populações que migravam dos campos. O Plano Director da Região de Lisboa (MOP , 1964) oferece boa ilustração da posição destes lugares no crescimento urbano da capital. No capítulo respeitante às zonas e sectores da cidade, esta zona é colocada entre a populosa «zona de aculturação», adjacente ao centro, e os subúrbios industriais mais afastados da urbe.

O Quadro 1 apresenta, em série, a população residente nas freguesias do Beato e Marvila entre 1864 e 1960. O ritmo de crescimento demográfico evidenciado remete para os ciclos de industrialização e para a condição industrial e portuária da zona, evidenciando também a sua quota-parte no crescimento urbano da capital. 
Quadro 1 População residente nas freguesias do Beato e Marvila (1864-1960)

\begin{tabular}{|l|l|l|l|l|l|}
\hline \multirow{2}{*}{ Freguesia } & \multicolumn{4}{l}{ Anos } \\
\cline { 2 - 6 } & 1864 & 1900 & 1920 & 1940 & 1960 \\
\hline Beato & 2408 & 10395 & 14850 & 16949 & 20129 \\
\hline Marvila* & - & - & - & - & 20001 \\
\hline
\end{tabular}

Fonte: INE, X RECENSEAMENTO GERAL DA POPULAÇÃO, 1960.

* FREgUeSIA CRIADA EM 1959.

As fontes de trabalho industrial e portuário, alimentadas pelas populações que se instalavam e adjuvadas, por exemplo, pelas associações e cooperativas que mediavam a relação entre os citadinos e a cidade, contribuíram para formar em Marvila e em seu redor uma particular "constelação" urbana (Park, 1984). A posição desta constelação na cidade foi durante boa parte do século XX sustentada pelas suas funções económicas, residenciais e de socialização urbana. A sua erosão é hoje bem patente. Perdeu-se actividade económica, apesar da luta contra os lay-offs e o encerramento de fábricas. Reduziu-se a vitalidade demográfica. Desagregou-se a estrutura de usos de solo (industrial e comercial, logístico e residencial) e com ela a consistência interna que sustentava a relação destes espaços com a cidade. Modificou-se a sua ligação à cidade com o desaparecimento do eléctrico. Parte significativa deste antigo "mar de chaminés e de gente" é hoje descrito como "cemitério de fábricas" e como um pequeno, envelhecido e invisível "mundo de resistentes" 2

Muitas das propriedades que outrora compunham este mundo urbano e operário desapareceram. Mas alguns vestígios podem ser encontrados em condições de "relativa invisibilidade" urbana e social (Baptista e Nunes, 2010: 56). A reportagem de Alexandra Lucas Coelho (2006), intitulada "Os resistentes de Marvila", desoculta traços e memórias desse mundo urbano. Indícios da vida citadina e industrial que modelou aquele lugar encontram-se nos depoimentos de velhos comerciantes e de dirigentes associativos locais. No texto, uma pluralidade de memórias é restituída: do movimento nas ruas ao mundo do trabalho, passando pela vitalidade dos lugares, bem expressa não só na sociabilidade dos seus antigos residentes como na oposição ao Estado Novo.

Parte da memória citadina e social destes lugares e seus residentes é tornada pública pela reportagem. O tom nostálgico da peça é duplamente significativo: eco dos depoimentos recolhidos e modo de transmitir uma particular atmosfera urbana e social que para os habitantes de Marvila e para muitos citadinos desapareceu. Como bem sublinha Ledrut (1968), a nostalgia é indiciadora de mudanças no modo de vida colectivo, mudanças às quais poderíamos acrescentar, em Marvila, a decomposição de um mundo social operário e as profundas transformações demográficas, económicas e culturais do meio social que ali junto ao Tejo resiste.

\section{A urbanização programada}

$15 \mathrm{Na}$ década de 60 , sobre as colinas cimeiras a Marvila, uma importante mudança urbanística ganhava forma: o Estado Novo dava seguimento ao programa de edificação 
de Habitação de Renda Económica. A promulgação do Decreto-Lei n. 42 454/59 deu um significativo seguimento ao programa já ensaiado em Alvalade, tendo a zona oriental de Lisboa sido eleita pelo município para a sua realização. Através deste programa, o governo pretendia produzir efeitos de ordem urbana e social na cidade e minorar a sublocação e a criação de bairros de lata (Nunes, 2007). Foi então criado o Gabinete Técnico de Habitação, que herdou o plano de Olivais Norte e concebeu os planos de Olivais Sul e de Chelas.

Quadro 2 População residente na freguesia de Marvila e cidade de Lisboa (1960-2011)

\begin{tabular}{|l|l|l|l|l|}
\hline \multirow{2}{*}{ População residente } & \multicolumn{4}{l}{ Anos } \\
\cline { 2 - 5 } & 1960 & 1981 & 2001 & $2011^{*}$ \\
\hline Marvila (freguesia) & 20001 & 40689 & 38767 & 38102 \\
\hline Lisboa (concelho) & 802230 & 807937 & 564657 & 547631 \\
\hline
\end{tabular}

Fonte: INE, X RECENSEAMENTO GERAL dA POPULAÇÃo, 1960; RECENSEAMENTO GERAL DA POPULAÇÃo 1981 e Censos 2001 e 2011.

* DAdOS PROVISÓRIOS, CENSOS 2011.

Este programa apresentava algumas semelhanças com iniciativas à época realizadas em França ou na Grã-Bretanha, onde as políticas de habitação surgiam associadas à institucionalização dos Estados-providência. Em Portugal, porém, a escala, a extensão social das populações-alvo e o volume de habitação produzido foram comparativamente menores. Todavia, a partir do trabalho realizado pelo GTH e pelos urbanistas ao seu serviço, integraram-se, formaram-se e consolidaram-se competências em arquitectura, urbanismo, engenharia e política social. Nos planos de Olivais Sul e de Chelas não foram apenas as experiências europeias que foram tidas em conta. A sensibilidade dos urbanistas e projectistas à cidade, à mudança social em curso e às suas mais carenciadas populações marcou em boa medida o seu urbanismo e a sua arquitectura (Nunes, 2007).

O Plano de Urbanização de Chelas (1964) deu continuidade à urbanização programada da zona oriental da cidade iniciada em Olivais Norte e prosseguida em Olivais Sul. Porém, o município carecia aí de solo municipalizado e enfrentava um grave problema de realojamento da população residente nos bairros de lata que durante a primeira metade do século XX foram ocupando as colinas e vales de Chelas (GTH, 1964).

Depois de Abril de 1974, foram em Chelas ensaiados e concretizados vários programas e políticas de habitação. A sua sequência e os seus instrumentos exerceram efeitos de triagem e fixação na composição da população residente neste grande sector da freguesia de Marvila. Assim, Chelas adquiriu uma especialização necessária e problemática: ser destino de famílias mal alojadas e pobres, algumas ali alojadas ao longo de várias gerações em condições miseráveis, outras recém-chegadas à urbe em condições de notória vulnerabilidade social. Este processo encontra tradução no crescimento demográfico da freguesia e no seu peso no povoamento da capital portuguesa, expresso no Quadro 2. 
19 Dos dados do Censos 2001 relativos ao estatuto de ocupação de alojamento na freguesia de Marvila recorta-se um efeito de estrutura residencial ${ }^{3}$.Uma significativa parte do parque habitacional da freguesia (13 mil alojamentos ocupados) é propriedade municipal ou estatal. Dois terços do parque habitacional da freguesia são alojamentos detidos por organismos públicos, contra $12 \%$ na cidade de Lisboa. A maioria dos habitantes de Marvila é arrendatária de um alojamento social gerido por burocracias estatais ou municipais.

20 Ao efeito de estrutura residencial junta-se a composição social do povoamento da freguesia. Os dados do Censos 2001 mostram que em Marvila se regista uma sobrerepresentação de activos operários com e sem qualificação (24\% em Marvila, $12 \%$ em Lisboa) e de "empregados e trabalhadores dos comércios e serviços com ou sem qualificação" (51\% em Marvila, 37\% em Lisboa). A proporção de activos sem qualificação, dentro deste último grupo socioeconómico, atingia $23 \%$, valor que recorta uma forte representação local face à cidade de Lisboa (12\%).

21 À diferenciação da estrutura residencial e da estrutura social da freguesia junta-se, em Chelas, uma difícil lisibilidade urbana (Lynch, 1990). É uma paisagem inacabada a que ali se oferece aos passantes, aos utilizadores e, sobretudo, aos habitantes. As formas edificadas, os vastos espaços livres por tratar e uma teia rodoviária tortuosa tornam difícil a leitura do espaço e a experiência quotidiana neste território.

\section{Marvila enquanto território de acção pública}

Várias estruturas da CML têm vindo a intervir neste território. O programa Viver Marvila, emanado de uma parceria entre o município e o IHRU, é uma das mais recentes e significativas acções. Compreende e alimenta uma série de programas locais: relativos à juventude e aos riscos sociais, à literacia informática e ao tempo livre de jovens e velhos, por exemplo. A criação de incentivos tendo em vista a localização de serviços e instituições públicas e privadas em Marvila é um objectivo perseguido ${ }^{4}$.

23 A condição simbólica do vasto e fragmentado espaço urbano de Chelas tem também sido objecto de reflexão e acção pública. A ruptura com algumas imagens jornalisticamente construídas tem sido activamente procurada. À imagem de um espaço inseguro e de conflitualidade entre residentes e a polícia e residentes entre si, propostas houve que procuraram reforçar a associação entre Marvila e os jovens originários dos bairros da freguesia que alcançaram o estrelato no mundo do futebol. Por outro lado, a transformação dos espaços públicos tem sido trabalhada: na renovação e criação de sinalética, regularização de passeios ou colocação de mobiliário urbano - acções nas quais a participação dos habitantes tem sido procurada 5 .

O grande conjunto residencial e os seus residentes enfrentam uma situação difícil na economia material e simbólica da metrópole de Lisboa. Em parte, devido à elevada especialização do solo para uso residencial, que determina uma condição urbana problemática e periférica. Porém, importa sublinhar que desde 1998 duas estações de metropolitano servem este território, sendo um recurso fulcral para uma futura qualificação do seu destino económico e social em Lisboa.

Também a zona ribeirinha de Marvila é hoje território de acção pública. "Cem milhões de euros para reabilitar a zona oriental" era o título de uma reportagem publicada em 2006 num jornal diário ${ }^{6}$.Aí se davam a conhecer os objectivos de uma Sociedade de 
Reabilitação Urbana criada em 2005 - i.e., um instrumento de política urbana concebido pelo Estado para articular e orientar investimento público e privado. No perímetro de intervenção desta SRU incluíam-se núcleos habitacionais degradados, nos quais, em Marvila e no Beato, afirmava a peça, residia população envelhecida, pouco escolarizada e com baixos rendimentos. Traços que remetem para a condição metropolitana de certas populações e que Gans (1962) tipificava como trapped.

Marvila e o Beato detêm hoje um legado urbano complexo e contraditório. Edifícios industriais tidos como obsoletos e abandonados, a par de espaços residenciais degradados, ali cotejam edificado com elevado valor fundiário e patrimonial: palácios e conventos, fábricas e armazéns. Os projectos de reabilitação destinados a transformar a forma e uso de alguns destes espaços revelam a tensa situação metropolitana da zona: entre a sua condição presente enquanto friche industrial e portuária degradada e as hipóteses de uma reabilitação futura, fundada sobretudo em investimentos que pretendem aproveitar os antigos perímetros fabris e a escala do edificado para promover habitação de gama superior.

Mas, sintomaticamente, Marvila tem vindo a ser transformada por iniciativas e apropriações protagonizadas por agentes implicados de modo mais ou menos off (Vivant, 2008) na economia cultural lisboeta. Como noutras zonas industriais e portuárias europeias, a economia cultural das cidades tem vindo a protagonizar alguns processos de transformação.

\section{Lisboa Capital do Nada e a Fábrica Braço de Prata}

Acções de revitalização da vida cultural e artística da cidade têm vindo a ocorrer em Marvila. Lisboa Capital do Nada, evento promovido pela Associação Extramuros em 2001, é disso exemplo. A iniciativa agregou múltiplas intervenções artísticas públicas, cujo grau de sucesso, enquanto tentativas quer de aproximação da população local à sua área de residência, quer de criação de usos alternativos do espaço, foi variado. Este projecto de arte pública tinha na sua génese o propósito de "criar, debater e intervir no espaço público" (Caeiro, 2010: 168). A participação da população e uma disposição para a vontade de conhecer o outro eram as linhas mestras previstas como subjacentes às intervenções artísticas.

O projecto contou com as criações de vários artistas: algumas mais directamente visíveis no espaço social e urbano de Marvila, como a obra-jardim de Fernanda Fragateiro, $O$ paraíso é um lugar onde nunca nada acontece, que consistiu no redesenho, com os habitantes, dos pequenos jardins abandonados junto ao conjunto residencial Pantera Cor-de-Rosa, em Chelas; outras mais simbólicas, como a peça de Francisco Tropa, que escolheu, com a verba que lhe foi atribuída no âmbito do projecto, mandar fazer um cilindro em ouro que entregou ao Presidente da Junta de Freguesia; outras ainda debruçavam-se sobre aspectos do quotidiano da população, como a peça Caminhos, de Mariana Viegas, que com um grupo de estudantes de uma escola secundária local traçou um conjunto de percursos diários que depois mapeou e apresentou numa exposição. Ainda no âmbito deste projecto surgiu a iniciativa "Sinais, a cidade habitada", que pretendeu instituir um conjunto de estruturas de sinalética local contando com a participação da população ao nível das escolhas de design de equipamento. 

Marvila é a reconversão da Fábrica Braço de Prata, que entre 1908 e os anos de 1990 laborou enquanto fábrica de armamento e hoje é um espaço de acolhimento à criação artística, à sua disseminação e ao debate cultural. Espaço emblemático da zona ribeirinha oriental da cidade e da sua história industrial, situa-se na baixa de Marvila, perto da qualificada zona de intervenção da EXPO'98 e do rio, integrando uma zona urbana deprimida. Entre um passado de produção industrial e um futuro incerto, um grupo de cidadãos decidiu aproveitar a antiga fábrica para incentivar um tipo diferente de produção: a cultural e artística. Ali se realizam debates e tertúlias e se programam concertos, espectáculos, workshops e a exibição de filmes, paredes meias com uma livraria e espaços para exposições.

31 O curso da Fábrica Braço de Prata tem sido atribulado. Sobre este complexo cultural impendeu o perigo de desalojamento, na sequência do projecto de habitações de luxo "Jardins Braço de Prata" de Renzo Piano, planeado para essa zona e aprovado pela CML em 2008. Porém, a autoridade pública decidiu manter o uso cultural do edifício, permitindo assim a continuação de um projecto que celebra por esta altura o seu $4 .{ }^{\circ}$ aniversário: " 4 anos experimentados desde o início como absolutamente improváveis", de sobrevivência ao "tempo, multas e à falência do próprio país", pode ler-se no website ${ }^{7}$.

O contraste entre dois projectos tão diferentes e para a mesma zona, um de âmbito residencial de gama alta e outro de pendor cultural de circuito off, é ilustrativo de duas formas de fazer cidade a que corresponderão destinos diferentes. A instalação de um projecto de âmbito artístico e cultural numa zona deprimida poderá, como sugere Vivant (2009), significar uma reorganização do sistema de produção local nas actividades culturais, substituindo as indústrias do passado e sendo alternativa à residencialização selecta prevista para o local. A ênfase na actividade artística e cultural menos programada institucionalmente e, portanto, de cariz off, é aqui central.

Os lugares culturais off constituem "espaces de la créativité artistique" e "constituent à la fois une respiration dans la ville" enquanto "zones de débauches", "lieux impromptus" ou "scènes de la marginalité et des surprises urbaines" (Vivant, 2009: 80). Em boa medida, tais lugares e suas qualidades são sólidos no que diz respeito a uma revitalização urbana eficaz. A espontaneidade é aqui sintomática de vitalidade e passível de atrair novos públicos, usos e actividades que se revertem numa mais-valia económica. Algo que Vivant defende não ser de todo reprodutível através de um elevado grau de planeamento (circuito in). Argumenta a autora que "un cadre formaté et planifié n'autorise pas cet espace de l'impromptu", e, acerca da planificação urbana, acrescenta que um desafio se lhe coloca:

Plutôt que de concevoir une ville créative, le défi de l'urbanisme est de créer les conditions de la sérendipité et de la créativité en laissant de l'espace à cet inconnu, en acceptant qu'apparaissent en ville des pratiques non planifiées, voire non autorisées, en rendant possibles les rencontres imprévues et improbables. (Vivant, 2009: 80)

Para o planeamento da cidade é de extrema importância a história da paisagem urbana, como sublinha Hayden, pois "both citizens and planners may find that urban landscape history can help to reclaim the identities of deteriorating neighbourhoods where generations of working people have spent their lives" (1995:43). Assim, urge um novo discurso e uma nova prática de planeamento urbano para Marvila, que não se esgotem apenas em grandes projectos arquitectónicos que têm em vista a revalorização urbana 
por meio da atracção de populações de alto poder socioeconómico com pouco interesse na partilha de espaços comuns com os residentes mais antigos. Em face da actual deterioração da zona, a criação de um pólo de produção artística e cultural será uma linha de intervenção com particular interesse, propiciando novas ambiências e vivências nesta zona da cidade. Uma revitalização urbana consciente da memória colectiva do lugar e dos percursos das suas populações é possível e poderá revelar-se inovadora se afirmar a importância das estruturas culturais e artísticas como qualificantes eficazes do espaço urbano. Em causa está, na formulação de Zukin (1995: 24), a criação de uma "public culture (that) involves both shaping public space for social interaction and constructing a visual representation of the city".

Num registo mais próximo à intervenção e à consultoria urbana, Landry e Bianchini (1998) advogam o fabrico de condições do que designam por Creative City. Entre as estruturas políticas e administrativas das cidades e a presença de meios criativos variavelmente estruturados, os autores identificam uma questão central, o acesso ao espaço, e argumentam:

A creative city requires land and buildings at affordable prices, preferably close to other cultural amenities. These are likely to be available in urban fringes and in areas where uses are changing, such as former port and industrial zones. Cheap spaces reduce financial risk and therefore encourage experiment. This has begun to happen in some old industrial areas close to city centres - for instance in the Duke Street area in Liverpool, Bradford's Little Germany and the Cultural Industries Quarter in Sheffield. (Landry e Bianchini, 1998: 30)

Como se viu, o fado de Marvila poderá compor-se por via não só do vasto património edificado existente como da sua reconversão em espaços criativos e de interesse artístico e cultural. Tal processo passaria pela regularização da situação de alguns projectos perante a estrutura político-adminstrativa da cidade. Assim se permitiria a estabilidade necessária para que possam desenvolver-se e contribuir de forma mais efectiva para que haja nova vida urbana nesta zona há tanto tempo deprimida e ocultada do olhar dos citadinos. Mas tal processo passaria também por uma renovada atenção por parte dos decisores públicos relativamente às condições de emergência de “meios criativos" (Landry e Bianchini, 1998: 26-31).

Tem aqui particular significado a integração de estruturas culturais de circuito off no planeamento urbano (Vivant, 2008). A sua captação para este estreito enclave social e económico alfacinha é condição fulcral. Projectos efémeros, como Lisboa Capital do Nada, ou permanentes, como se desejaria que a Fábrica Braço de Prata o fosse, constituem ainda pequenas "ilhas" de actividade numa zona densa em edificado, já dotada de alguns equipamentos culturais, e com tão poucas pessoas para os viverem. Através da sua capacidade para captar fluxos e usos originários de residentes, utilizadores e visitantes da metrópole no seu todo, estes e outros projectos poderiam fazer com que Marvila e o Beato entrevissem um outro fado, tornando-se freguesias vivas de cultura e pessoas, escapando à sua condição urbana expectante e indecisa em relação ao futuro e ao passado.

\section{Discussão e notas finais}

Hoje, um viajante que chegue a Lisboa de comboio tem a opção de sair na Gare do Oriente - uma importante plataforma de mobilidade na metrópole lisboeta. Em seu redor, uma paisagem facilmente reconhecível: sedes de empresas e hotéis, serviços 
públicos e privados de gama alta, um centro comercial e uma profusão de sinalética indicando o caminho para equipamentos, lugares de lazer e atracções turísticas. Tal viajante com facilidade se apercebe de uma atmosfera particular, constituída pelo trabalho no sector dos serviços, pela procura de serviços ali sediados e pelo lazer e consumo, não poucas vezes turístico e praticado por diferentes grupos sociais. Estas são actividades que engendram "formas de ocupação do espaço" típicas dos centros urbanos (Castells, 1984) e associadas a funções com elevada posição na hierarquia urbana. Aqui, como noutras cidades um pouco por todo o mundo, uma série de operações de "renovação de frente de água", combinando investimento público e privado, foi orientada para o fabrico de uma nova centralidade metropolitana.

Marvila e a frente ribeirinha oriental de Lisboa apresentam, hoje como outrora, uma condição in between. Anteriormente, Marvila marcava posição entre a Baixa, a "zona de transição" e os núcleos suburbanos industriais mais distantes. Agora, a sua posição na metrópole joga-se entre o Parque das Nações e a Baixa, entre Chelas e o porto de Lisboa e o Tejo. No seio deste mosaico urbano, expressão da Escola de Chicago, uma condição de "relativa invisibilidade urbana" (Baptista e Nunes, 2010) sobreveio sobre Marvila e o mundo social dos seus residentes.

40 A história da urbanização programada e da acção pública que têm tido Marvila como território de intervenção exprime bem um particular regime de "economia política urbana" (Fijalkow, 2009). Foi através de um grande programa público de habitação, iniciado nos anos de 1960 com o Plano de Urbanização de Chelas e prosseguido em moldes diversos nas décadas seguintes, que Marvila adquiriu uma especialização necessária e problemática na metrópole. Constituiu-se como território de política habitacional dirigida às populações mais desmunidas de recursos económicos e sociais. Hoje, as acções que integram o programa Viver Marvila e a projectada reabilitação urbana dos espaços industriais junto ao Tejo tentam modificar a distribuição de oportunidades e de recursos, que historicamente modelou a descontinuidade social e territorial que esta zona de Lisboa enfrenta.

41 A este propósito, Zukin (1995: 7) salienta que "the look and feel of cities reflect decisions about what - and who - should be visible and what should not, on concepts of order and disorder, and on uses of aesthetic power". A possibilidade de Marvila e os seus espaços serem revitalizados ou, em alternativa, "reabilitados", no sentido de tornados aptos a uma exploração económica assente na reconversão fundiária e residencial, é particularmente incidente na visibilidade, na ordem social e urbana e no uso do poder sobre a paisagem. A "reabilitação" para exploração fundiária capitalista será decerto determinante do destino deste território na metrópole de Lisboa. Mas sêlo-ão também as hipóteses de revitalização decorrentes de iniciativas provenientes da economia cultural, e sobretudo de circuitos culturais off, indiciadoras da constituição de uma nova ordem urbana local.

42 A articulação entre as actividades culturais e os antigos espaços industriais constitui aqui sinal da emergência de creative spaces (Landry e Bianchini, 1998). A sua dinâmica interpela as estruturas político-administrativas da urbe lisboeta, requerendo-lhes decisões. No fundo, trata-se de saber como é que a herança industrial e operária, nas suas dimensões espaciais e materiais, sociais e simbólicas, é tornada parte do destino do território de Marvila e constituída como memória colectiva.

Em causa está conhecer os modos como a "produção do espaço" se articula com "a construção social do lugar" (Low, 2000). No pólo da construção, sabe-se que uma das 
características nucleares do conceito de lugar é a de lhe ser inerente uma atribuição de sentido. De entre uma variada, porém limitada, gama de significações que podem ser atribuídas ao espaço no fabrico de um lugar, as que são engendradas a partir da memória colectiva assumem particular relevo (Boyer, 1996). As condições sociais nas quais os grupos sociais residentes em Marvila podem estabelecer a partir do espaço a sua memória colectiva, e os seus traços espaciais e económicos, sociais e simbólicos, são tão precárias quanto cruciais no destino da freguesia.

A relação entre a memória dos lugares e o papel dos citadinos no seu fabrico é central para Hayden, que afirma:

Place memory encapsulates the human ability to connect with both the built and natural environments that are entwined in the cultural landscape. It is the key to the power of historic places to help citizens define their public pasts: places trigger memories for insiders, who have shared a common past, and at the same time places often can represent shared pasts to outsiders who might be interested in knowing about them in the present (Hayden, 1995: 46).

o sentimento nostálgico que os edifícios das antigas fábricas e que o trabalho e o movimento que deram vida àquele território evocam aos "resistentes" de Marvila é reflexo de uma passiva contemplação sobre um passado que já não existe. Porém, tal sentimento é uma via para que o destino metropolitano deste e de outros lugares da frente ribeirinha oriental de Lisboa seja seguramente ancorado na memória colectiva e pública da metrópole.

\section{BIBLIOGRAFIA}

BAPTISTA, Luís V. e J. P. S. Nunes (2010), “Lisboa invisível. Notas sobre a descoultação de microdinâmicas metropolitanas”, in A. Dornelas, L. Oliveira, L. Veloso e M. D. Guerreiro (orgs.), Portugal Invisível, Lisboa, Mundos Sociais, pp. 53-74.

BOYER, M. C. (1996), The City of Collective Memory. Its Historical Imagery and Architectural Entertainments, Cambridge (MA), The MIT Press.

CAEIRO, M. (2010), “Arte Crítica Urbana. De Lisboa como Capital do Nada à Luz Boa da Cidade... Experiências Extramuros”, in AAVV, Arte Pública e Cidadania, Casal de Cambra, Caleidoscópio, pp. 162-182.

CASTELLS, M. (1984), Problemas de Investigação em Sociologia Urbana, Lisboa, Presença.

COELHO, A. L. (2006), “Os resistentes de Marvila”, Pública, 506, 5 de Fevereiro de 2006, pp. 44-57.

FERRÃO. J. et al. (2003), “Uma metrópole em transição: novo perfil produtivo, novos espaços económicos", in J. A. Tenedório (dir.) Atlas da Área Metropolitana de Lisboa, Lisboa, AML, pp. 167-187.

FERREIRA, V. M. (1986), A Cidade de Lisboa: de Capital do Império a Centro da Metrópole, Dissertação de Doutoramento em Sociologia, Lisboa, ISCTE. 
FIJALKOW, Y. (2009), “Politiques urbaines”, in J.-M. Stébé e H. Marchal (dirs.), Traité sur la Ville, Paris, PUF, pp. 153-205.

FOLGADO, D. e J. Custódio (1999), Caminho do Oriente. Guia do Património Industrial, Lisboa, Livros Horizonte.

GABINETE TÉCNICO DE HABITAÇÃo (1964), Plano de Urbanização de Chelas, Lisboa, CML.

GANS, H. (1962), "Urbanism and suburbanism as ways of life”, in A. M. Rose (ed.), Human Behaviour and Social Process, Londres, Routledge and Kegan Paul, pp. 625-648.

HAYDEN, D. (1995), The Power of Place: Urban Landscapes as Public History, Cambridge, The MIT Press.

LANDRY, C. e F. Bianchini ([1995] 1998), The Creative City, Londres, Demos.

LEDRUT, R. (1968), Sociologie Urbaine, Paris, PUF.

LOW, S. (2000), On the Plaza. The Politics of Public Space and Culture, Austin, University of Texas Press.

LYNCH, K. ([1960] 1990), A Imagem da Cidade, Lisboa, Edições 70.

MAGRI, S. e C. Topalov (1989), "Pratiques ouvrières et changements structurels dans l'espace des grandes villes du premier XXe siècle. Quelques hypothèses de recherche”, in S. Magri e C.

Topalov (dir.), Villes Ouvrières - 1900-1950, Paris, L'Harmattan, pp. 17-40.

MATOS, J. S. (1999), “Prefácio”, in Folgado, D. e J. Custódio (1999), Caminho do Oriente. Guia do Património Industrial, Lisboa, Livros Horizonte, p. 5.

MINISTÉRIO DAS OBRAS PÚBLICAS (1964), Plano Director da Região de Lisboa. Anteplano, volume I. Memória Descritiva e Justificativa, Lisboa, MOP/Conselho Superior de Obras Públicas.

NUNES, J. P. S. (2007), À escala humana: planeamento urbano e arquitectura de habitação em Olivais Sul (Lisboa, 1959-1969), Lisboa, CML.

PARK, R. E. ([1916] 1984), “La ville. Propositions de recherche sur le comportement humain en milieu urbain”, in Y. Grafmeyer e I. Joseph (orgs.) L'École de Chicago. Naissance de l'écologie urbaine, Paris, Aubier, pp. 83-130.

SALGUEIRO, T. B. (2001), Lisboa, Periferia e Centralidades, Oeiras, Celta.

TRAQUINO, M. (2010), A Construção do Lugar pela Arte Contemporânea, Ribeirão, Húmus.

VIVANT, E. (2008), Le Rôle des Pratiques Culturelles Off dans les Dynamiques Urbaines, tese de doutoramento em Urbanismo, Paris 8.

VIVANT, E. (2009), Qu'est-ce que la ville créative?, Paris, PUF.

ZUKIN, S. (1993), Landscapes of Power. From Detroit to Disney World, Berkeley, UCP.

ZUKIN, S. (1995), The Cultures of Cities, Oxford, Blackwell.

\section{NOTAS}

1. República, «A Lisboa que trabalha», 15 de Maio de 1940.

2. Ver «A Lisboa que trabalha», República, 15 de Maio de 1940, o site da Junta de Freguesia do Beato, http://jf-beato.pt/beato/historia/, acedido a 1 de Junho de 2011, e Coelho (2006). 
3. Fazemos uso dos dados definitivos do Censos 2001 porque os dados provisórios disponíveis do Censos 2011 não permitem evidenciar estes dois efeitos.

4. Informações transmitidas pelo Presidente da Junta de Freguesia de Marvila, senhor Belarmino Silva, em entrevista a um dos autores, a 7 de Março de 2011.

5. Acções comunicadas e discutidas nos Congressos Marvilenses e apresentadas no site da Junta de freguesia de Marvila (http://jf-marvila.pt, no separador "Congressos").

6. Diário de Notícias, 18 de Agosto de 2006, reportagem da autoria de Ana Mafalda Inácio.

7. http://bracodeprata.net/ (1 de Junho de 2011).

\section{RESUMOS}

Este artigo descreve e analisa o destino metropolitano de Marvila, uma das mais antigas zonas industriais e operárias de Lisboa. Primeiro, reconstitui a história do seu território e da sua ocupação, analisa a sua ascensão e queda industrial e dá a conhecer um sentimento nostálgico que a sua situação presente gera nalguns dos seus residentes. Depois, analisa o histórico de acção pública no território da freguesia e a sua relação com os espaços, actividades e populações residentes. Em seguida, apreende duas acções inscritas na economia cultural e no meio social urbano de Marvila - Lisboa Capital do Nada e Fábrica Braço de Prata - discutindo-as à luz das propriedades dos circuitos culturais off e dos creative spaces e enquanto valia na revitalização da freguesia. No final, são objecto de reflexão os vestígios e os efeitos do passado industrial de Marvila na memória colectiva das populações, e a forma como ambas participam no destino dos seus espaços de vida quotidiana.

This article describes and analyzes the metropolitan destiny of one of Lisbon's oldest industrial and working class districts - Marvila. Firstly, it focuses on the history of the district and its occupation, analyzes the area's industrial rise and fall, and gives an account of the nostalgia that its present condition engenders in some of its residents. Secondly, it analyses the history of public action carried out in the territory of the district and its relationship with Marvila's spaces, activities and population. Thirdly, it captures Lisboa Capital do Nada and Fábrica Braço de Prata as two elements embedded in Marvila's cultural economy and urban social milieu, discussing them from both the off artistic circuit and the creative spaces perspectives. Finally, a reflection on both the remains and the effects of Marvila's industrial past is offered, bearing on Marvila's collective memory and population, and on how they both participate in the destiny of its spaces of daily life.

\section{ÍNDICE}

Keywords: Lisbon, metropolis, collective memory, urban renewal, cultural circuits

Palavras-chave: Lisboa, metrópole, memória colectiva, reabilitação urbana, circuitos culturais 


\section{AUTORES}

\section{JOÃO PEDRO SILVA NUNES}

ISCTE - Instituto Universitário de Lisboa, DINÂMIA-CET/IUL, Investigador Ciência 2008

joao.silva.nunes@iscte.pt

\section{ÁGATA DOURADO SEQUEIRA}

ISCTE - Instituto Universitário de Lisboa, Doutoranda em Sociologia

agata.sequeira@gmail.com 